Published in final edited form as:

Calcif Tissue Int. 2008 August ; 83(2): 146-154. doi:10.1007/s00223-008-9164-z.

\title{
A Comparison of the Physical and Chemical Differences Between Cancellous and Cortical Bovine Bone Mineral at Two Ages
}

\author{
Liisa T. Kuhn, \\ Laboratory for the Study of Skeletal Disorders and Rehabilitation, Department of Orthopedic \\ Surgery, Children's Hospital, Harvard Medical School, Boston, MA, USA \\ Marc D. Grynpas, \\ Samuel Lunenfeld Research Institute, Mt. Sinai Hospital, Toronto, Canada \\ Christian C. Rey, \\ Laboratoire de Physico-Chimie des Solides, Centre National de la Recherche Scientifique, \\ Toulouse, France \\ Yaotang $\mathbf{W u}$, \\ Laboratory for the Study of Skeletal Disorders and Rehabilitation, Department of Orthopedic \\ Surgery, Children's Hospital, Harvard Medical School, Boston, MA, USA; Biomaterials Laboratory, \\ Martinos Center, Department of Radiology, Massachusetts General Hospital, Charlestown, MA, \\ USA \\ Jerome L. Ackerman, and \\ Laboratory for the Study of Skeletal Disorders and Rehabilitation, Department of Orthopedic \\ Surgery, Children's Hospital, Harvard Medical School, Boston, MA, USA, Biomaterials Laboratory, \\ Martinos Center, Department of Radiology, Massachusetts General Hospital, Charlestown, MA, \\ USA
}

Melvin J. Glimcher Laboratory for the Study of Skeletal Disorders and Rehabilitation, Department of Orthopedic Surgery, Children's Hospital, Harvard Medical School, Boston, MA, USA

\begin{abstract}
To assess possible differences between the mineral phases of cortical and cancellous bone, the structure and composition of isolated bovine mineral crystals from young (1-3 months) and old (4-5 years) postnatal bovine animals were analyzed by a variety of complementary techniques: chemical analyses, Fourier transform infrared spectroscopy (FTIR), X-ray diffraction (XRD), and ${ }^{31} \mathrm{P}$ solid-state magic angle spinning nuclear magnetic resonance spectroscopy (NMR). This combination of methods represents the most complete physicochemical characterization of cancellous and cortical bone mineral completed thus far. Spectra obtained from XRD, FTIR, and ${ }^{31} \mathrm{P}$ NMR all confirmed that the mineral was calcium phosphate in the form of carbonated apatite; however, a crystal maturation process was evident between the young and old and between
\end{abstract}

L. T. Kuhn, Department of Reconstructive Sciences, University of Connecticut Health Center, MC1615, Farmington, CT 06107, USA, lkuhn@uchc.edu. 
cancellous and cortical mineral crystals. Two-way analyses of variance showed larger increases of crystal size and $\mathrm{Ca} / \mathrm{P}$ ratio for the cortical vs. cancellous bone of 1-3 month than the 4-5 year animals. The $\mathrm{Ca} /\left(\mathrm{P}+\mathrm{CO}_{3}\right)$ remained nearly constant within a given bone type and in both bone types at $4-5$ years. The carbonate and phosphate FTIR band ratios revealed a decrease of labile ions with age and in cortical, relative to cancellous, bone. Overall, the same aging or maturation trends were observed for young vs. old and cancellous vs. cortical. Based on the larger proportion of newly formed bone in cancellous bone relative to cortical bone, the major differences between the cancellous and cortical mineral crystals must be ascribed to differences in average age of the crystals.

\section{Keywords}

Bone mineral; Cancellous; Cortical; Trabecular; Aging; Crystallinity; Fourier transform infrared spectroscopy; X-ray diffraction; Solid-state nuclear magnetic resonance

The structure and composition of the mineral phase of bone and the maturational changes that occur with time have been the focus of many studies. Knowledge of the precise structure and composition of bone and its change with age is vital for distinguishing differences due to medication or disease and for providing a bone mineral model for synthetic replacements. However, the precise structure of the mineral phase continues to elude those who seek it. The current consensus from the literature is that bone mineral is a poorly crystalline, nanocrystalline carbonated apatite, with no other detectable calcium phosphate phases present, and contains various ionic and cationic substitutions, such as $\mathrm{HPO}_{4}, \mathrm{Na}$, and $\mathrm{Mg}[1$, 2]. There have been reports by us, and others, of additional mineral phases present (e.g., amorphous or brushite [3]), but they have later been discounted because processing conditions that do not preserve the native bone mineral structure were used in the studies [4]. Although bone mineral is often referred to as "hydroxyapatite" in the literature, this is a misnomer of sorts since several studies indicate the near to complete absence of hydroxyl groups in bone mineral [5-7]. A recent nuclear magnetic resonance (NMR) study reports a detectable hydroxyl ion presence [8], albeit reduced from that predicted by the theoretical stoichiometry of hydroxyapatite. Hydroxyl groups are formed in bone mineral when it is heated to high temperatures, and historically, this was done via ashing, to isolate the bone mineral for further study. Surface water layers on the mineral may also appear as hydroxyl groups, leading to further confusion [9]. Hence, bone mineral became known as "hydroxyapatite," but actually bone mineral is a unique form of carbonated apatite and includes unique protonated phosphate groups not found in synthetic apatites [10,11].

Not surprisingly, the chemical and physical structure of bone mineral is not static in the aqueous in vivo environment but evolves with age. The crystals undergo a subtle maturational process that includes the following: the $\mathrm{Ca} /(\mathrm{P}+\mathrm{C})$ molar ratio increases [1215], the carbonate and $\mathrm{HPO}_{4}$ content of bone mineral increases [16-20], the indices of crystallinity increase [21-24], the crystal size increases, and the concentrations of labile $\mathrm{HPO}_{4}$ and $\mathrm{CO}_{3}$ ions decrease [25-30]. Bone mineral also appears to be different depending on where it is located in the same bone (e.g., cancellous vs. cortical). The studies that have assessed the differences in the mineral component of cortical and cancellous bone have 
found, in general, that the differences in cancellous and cortical bone mirror those differences between young and old bone, respectively [12, 14, 30-33]. A study on isolated rat cortical and trabecular (i.e., cancellous) bone concluded that cancellous bone displays a reduced $\mathrm{Ca} / \mathrm{P}$ molar ratio, carbonate content, and average crystal size as well as a greater extent of thermal conversion into $\beta$-tricalcium phosphate than cortical bone, indicating different ion substitutions [12]. The crystals were isolated from the organic matrix in that study because when bone mineral is analyzed intact with the organic matrix component, it is difficult to identify the boundary of where bone mineral ends and where the organic matrix or water begins. Unfortunately, this study utilized typical methods to separate the mineral component from the organic phase, which involve high-temperature processing with aqueous solvents and introduce artifacts due to the extreme instability of bone mineral, in particular the newly formed crystals. Therefore, in this study we utilized mild, lowtemperature, nonaqueous methods [34] in moderation.

In addition to wet chemical analysis methods, Fourier transform infrared (FTIR) spectroscopy is an alternative technique for revealing subtle structural and chemical maturational changes $[14,16,25,30]$. This technique had been used extensively to analyze ground powders $[15,16,25]$, but the coupling of the spectrometer with a light microscope [30] (FTIR microspectroscopy) and the addition of an array detector [35] (FTIR microspectroscopic imaging) enabled rapid acquisition of semiquantitative data at specific sites within the mineralized tissues. An FTIR microspectroscopic study on intact bone showed that human cortical bone mineral has a more hydroxyapatite-like stoichiometry, a bigger crystallite size, and less ion substitution than cancellous bone [30]. A study on mouse bones by the same group, using the same FTIR microscopic methods, determined that cortical bone crystals were larger and more perfect than those of cancellous bone [15]. Studies with FTIR microspectroscopic imaging reported distributions in carbonate [36] and carbonate content $[37,38]$ as well as types of carbonate substitution $[39,40]$. Hence, these FTIR studies could distinguish that mineral in the center of a trabecula was more crystalline than that in the outer layers and that mineral in the center of an osteon or near the periosteal side was less crystalline than that in the outer osteonal layers or near the medullary canal $[15,30]$. By their nature, FTIR techniques provide validated [35, 41] semiquantitative, rather than quantitative, information; therefore, in the present study we utilized a combination of six different characterization methods to fully quantify and describe average differences in young and old, cortical and cancellous bone mineral. In addition to characterizing the mineral by FTIR and X-ray diffraction (XRD), solid-state magic angle spinning differential cross-polarization ${ }^{31} \mathrm{P}$ NMR spectroscopy was utilized to study the $\mathrm{HPO}_{4}$ groups of the young and old cancellous and cortical bone. This technique provides data on the isotropic and anisotropic chemical shifts and cross-polarization rates and has been used to identify the unique characteristics of $\mathrm{HPO}_{4}$ groups in bone apatites not present in any of the other synthetic calcium phosphate crystals containing $\mathrm{HPO}_{4}$ studied [10, 11, 42]. This and related solid-state NMR spectroscopic techniques provide data on the isotropic and anisotropic chemical shifts, cross-polarization rates, and spin-spin couplings and has been used to characterize $\mathrm{PO}_{4}$ and $\mathrm{HPO}_{4}$ groups in bone apatite [10, 42-44]. 


\section{Materials and Methods}

\section{Crystal Isolation}

Frozen bovine tibias and femurs from animals 1-3 months or 4-5 years old were obtained from Research 87 (Boston, MA). The bones were dissected out and cleaned free of soft tissues. The midshafts (diaphyses) were separated from the metaphyses and then rinsed with ethanol and ether. Cortical bone samples were prepared from midshaft bone sections. Cancellous bone samples were obtained from metaphyseal bone. Bones from several animals of the same age or bone type were combined together to create the samples analyzed due to the length of time required to process large samples by the low-temperature, nonaqueous methods [34]. Bones (from both hind limbs) from 15 animals were used for the 1-3 month group and from five animals for the 45 year group. As such, the parameters measured reflect average, pooled values. Replicate analysis of samples was done to determine means and standard deviations. Bone chips were obtained by hammering or using an industrial blender with ethanol. The chips were further ground in a liquid nitrogen-cooled SPEX 6700 freezer/mill (SPEX CertiPrep, Metuchen, NJ) to obtain a starting material with a particle size less than 200 mesh. The samples were first defatted in 2:1 (v:v) chloroform and methanol (1 g powder to $10 \mathrm{~mL}$ liquid). Following the procedure of Kim et al. [34], defatted bone powder was plasma-ashed in an oxygen plasma for 40 days to degrade the organic matrix components. The samples were stirred every fifth day to assure uniform ashing. It has been shown that these techniques, when used in moderation, do not affect the structure or composition of calcium phosphate phases including brushite, octacalcium phosphate, and poorly crystalline carbonated apatite [34].

\section{Chemical Analyses}

Calcium, phosphorous, and other ion content was determined by electron microprobe analysis as follows. Isolated bone mineral crystals $(85 \mathrm{mg})$ were pressed into a flat pellet using a handheld pellet press. The settings for the Cameca Instruments (Nampa, ID) MBX electron microprobe were: $10 \mathrm{KeV}$ beam voltage, $30 \mathrm{nA}$ beam current and a rastered beam of $64 \times 64 \mu \mathrm{m}$. The software program Sandia ZAF85 was used for matrix corrections, assuming stoichiometric oxygen for $\mathrm{Na}, \mathrm{Mg}, \mathrm{P}$, and $\mathrm{Ca}$. Five to 10 analyses were obtained per pellet. The carbonate ion content was determined by coulometry (UIC Coulometrics) [45], in which $\mathrm{HCl}$ is used to evolve $\mathrm{CO}_{2}$ from the inorganic component of the sample. Three replicates were performed. From the determination of calcium, phosphate, and carbonate, $\mathrm{Ca} / \mathrm{P}, \mathrm{Ca} /(\mathrm{P}+\mathrm{C}$ ) (since carbonate substitutes for phosphate), and $\mathrm{C} / \mathrm{P}$ atomic ratios were calculated in order to follow chemical composition evolution in the bone samples of different ages and types.

Residual protein content of the deproteinized samples was determined based on amino acid analysis of acid hydrolysates $\left(6 \mathrm{~N} \mathrm{HCl}, 110^{\circ} \mathrm{C}, 24 \mathrm{~h}\right)$ of $10 \mathrm{mg}$ of isolated crystals using a Beckman (Fullerton, CA) model 121-M amino acid analyzer, from which the total protein and collagen contents were calculated. 


\section{Spectral Analyses}

XRD—Each powdered sample was spread in a thin, even layer on a quartz crystal sample holder for X-ray diffraction (Rigaku MultiFlex; Rigaku/MSC, Woodland, TX) scans, using $\mathrm{CuKa}$ radiation at $40 \mathrm{kV}$ and $40 \mathrm{~mA}$. Samples were scanned from 24.5 to $27.0^{\circ}(2 \theta)$ at a scan speed of $0.1^{\circ}$ per minute for crystal length (002). Additionally, samples were scanned from 37.0 to $42.0^{\circ}(2 \theta)$ at a scan speed of $0.05^{\circ}$ per minute for crystal cross section (130). A highly crystalline mineral fluoroapatite was used as a standard. Three replicate measurements were performed.

Crystal size/strain is associated with the broadening of the apatite peaks at relevant angles; this broadening is estimated by measuring the full width at half the maximum height of the apatite peaks $\left(\beta_{1 / 2}\right)$, using Materials Data (Livermore, CA) Jade XRD pattern processing software (Win-OS V5). However, peak broadening can also be affected by instrument broadening. $\beta_{1 / 2}$ was thus appropriately adjusted using values obtained from the fluroapatite standard. These corrected $\beta_{1 / 2}$ values were then used in the Scherrer equation [46] to calculate $D$ values, which are related to the crystal length (002) and crystal cross section (130). Both the small size of the crystals and the imperfections in the crystals are associated with peak broadening. Since it is not possible to separate out these effects, a crystallinity parameter was not calculated.

FTIR Spectroscopy-FTIR spectra were recorded from isolated crystals in $\mathrm{KBr}$ pellets using a Perkin-Elmer (Oak Brook, IL) 1760-X spectrometer. Estimates of the labile phosphate components were made using band area ratios obtained after decomposition of the $v_{4} \mathrm{PO}_{4}$ band [25]. Labile ions have nonapatitic environments and are associated with a hydrated layer at the surface of the nanocrystals in aqueous media [29]. The carbonate intensity ratios (typeA/typeB, $878 / 871 \mathrm{~cm}^{-1}$; type $\mathrm{C} /$ type $\mathrm{B}, 866 / 871 \mathrm{~cm}^{-1}$ ) and a resolution factor $(\mathrm{RF})$ indicating crystallinity were calculated from deconvoluted carbonate peaks in the $v_{2}$ carbonate domain $[17,47]$. Samples were analyzed immediately after deproteinization processing to ensure dryness. The standard errors are $<1 \%$ on the height and width for the bands of interest.

31P Solid-State NMR Spectroscopy-Measurements were carried out on a Bruker (Billerica, MA) MSL-400 NMR spectrometer, equipped with a 9.4 Tesla field strength magnet, yielding proton and phosphorus frequencies of 400.13 and $161.98 \mathrm{MHz}$, respectively. A Bruker solid-state magic angle-spinning (MAS) probe with $\mathrm{B}_{1}$ fields of 50$60 \mathrm{kHz}$ was used with a sample rotation speed of $4.5-5.0 \mathrm{kHz}$. The forward crosspolarization (CP) time was $300 \mu$ s for all CP and differential CP (DCP) experiments. The reverse DCP time varied from 290 to $320 \mu$ s. The number of scans averaged for each spectrum was 1,200 , and the recycle delay was $10 \mathrm{~s}$.

\section{Statistical Analysis}

Comparison between treatment groups involved the calculation of means, standard deviations, and errors and analysis of variance (two-way ANOVA to compare bone type and age effect on the outcome variables). Statistical analysis was performed using the statistical package Prism 4.0 (GraphPad Software, La Jolla, CA). 


\section{Results}

\section{Long-Range Order and Chemical Composition}

The XRD spectra of the four isolated crystal samples are shown in Fig. 1. The peaks are consistent with those of apatite for both the young and old and cancellous and cortical samples. The triple peak of apatite was not resolved due to the peak broadening from the low crystallinity and nanocrystallinity of the bone samples. From the 002 and 130 peaks the crystal lengths and cross-sections were calculated and are shown in Table 1. Statistical analysis showed a significant interaction between age on the values for bone type for both crystal sizes. The older crystals are "larger and/or more perfect" than the younger crystals of the same bone type $(002, P<0.0001 ; 130, P<0.0001)$. The cortical bone mineral crystals are "larger and/or more perfect" than the cancellous bone crystals $(002, P<0.0001 ; 130, P=$ 0.01 ) for the younger bone crystals but not the older.

The residual organic content of the samples after 40 days of plasma ashing is shown in Table 2. The cancellous bone mineral samples contained $10 \%$ and $14.6 \%$ residual protein (young and old, respectively), while the cortical samples were reduced to 2.3 and 3.8\% (young and old, respectively). Since the deproteinization procedures were identical, the lower protein content of the cortical samples most likely reflects the higher original mineral to matrix ratio in the cortical samples and/or differences in sample porosity. The most abundant amino acids present in the most fully deproteinized cortical sample were proline (314 residues/ $1,000)$ and hydroxyproline (273 residues/1,000).

The $\mathrm{Ca} / \mathrm{P}$ ratios for the cancellous and cortical bone mineral were 1.51 and 1.61 for the younger bone and 1.58 and 1.64, respectively, for the older bone (Table 2). Highly significant differences $(P<0.01)$ were found between $1-3$ month cancellous versus $1-3$ month cortical and 1-3 month cancellous versus $4-5$ year cortical. Significant differences $(P$ $<0.05$ ) were found for 4-5 year cancellous versus 4-5 year cortical and 1-3 month cancellous versus 4-5 year cancellous. No significant difference was found between 1-3 month cortical versus 4-5 year cancellous and 1-3 month cortical versus 4-5 year cortical, indicating comparable maturation with regard to this parameter. The carbonate content increased with age $(P=0.0001)$, but between cancellous and cortical bone types this did not always hold true $(P=0.06)$. The $\mathrm{Ca} /\left(\mathrm{P}+\mathrm{CO}_{3}\right)$ values showed a difference at $1-3$ months between cancellous and cortical $(P=0.003)$ but were similar at 4-5 years and similar within a given bone type $(P=0.4)$. The $\mathrm{CO}_{3} / \mathrm{P}$ atomic ratio did not increase with age.

\section{FTIR Spectroscopy}

FTIR spectra from the four samples are shown superimposed in Fig. 2. The patterns are similar and all apatitic. Differences between the samples are evident after deconvolving and decomposing the carbonate and phosphate domains. The ratios type A/type B and type $\mathrm{C}($ labile)/type $\mathrm{B}$ carbonate are shown in Table 2 . There is a greater proportion of type A carbonate and relatively fewer labile $\mathrm{CO}_{3}$ ions in the older bone. The carbonate $\mathrm{RF}$ is higher for the older cortical bone. The relative infrared band intensities of labile $\mathrm{HPO}_{4}$ and $\mathrm{PO}_{4}$ are shown in Table 2 . The interaction between age is considered extremely significant for the $\mathrm{HPO}_{4}$ bands $(P<0.0001)$; hence, age does not have the same effect at all values of bone 
type. There is significantly more labile $\mathrm{HPO}_{4}$ in the 1-3 month cancellous than the $4-5$ year cancellous bone $(P<0.0001)$, while the labile $\mathrm{HPO}_{4}$ content is very similar between $4-5$ year cancellous and cortical (Table 3 ).

\section{${ }^{31}$ P NMR Spectroscopy}

The normal $\mathrm{CP}^{31} \mathrm{P}$ MAS NMR spectra are shown in Fig. 3. All four samples exhibit the $\mathrm{PO}_{4}$ chemical shift (3.1 ppm) and sidebands characteristic of apatite. The broad peak width indicates the material is poorly crystalline. The differential $\mathrm{CP}^{31} \mathrm{P}$ MAS NMR spectra are shown in Fig. 4. The inverted spinning sideband pattern is that of $\mathrm{HPO}_{4}$, which is past its null for this particular value of reverse $\mathrm{CP}$ time. The narrow positive-going feature overlapping the $\mathrm{HPO}_{4}$ centerband is the centerband of $\mathrm{PO}_{4}$. The $\mathrm{PO}_{4}$ signal has not quite reached its null point because of the slower $\mathrm{CP}$ rate of $\mathrm{PO}_{4}$ (in which protons are distant from the phosphorus) compared to $\mathrm{HPO}_{4}$ (in which a proton is near the phosphorus). The spectral characteristics of the $\mathrm{HPO}_{4}$ including the anisotropic chemical shift are characteristic of that for bone mineral. In all four samples, the first-order upfield spinning sidebands are more intense than the first-order downfield sidebands, indicating that these phosphorus atoms are closely associated with calcium ion [42], as of course they would be in apatite crystals, and do not arise from other sources of phosphorus (e.g., protein-linked phosphonate moieties) not complexed with calcium. The upfield-to-downfield sideband height ratio of the cancellous samples (roughly 2.0) was slightly larger than the ratio for the cortical samples (roughly 1.8), whereas there was no discernable difference in the ratio between the young and old samples. This could be an indication of subtle differences in the phosphate environments between the cortical and cancellous samples. The linewidths of all four specimens are essentially identical.

\section{Discussion}

In this study we have characterized the physicochemical features of bone mineral from young and old, cortical and cancellous bovine bone that has been isolated from the organic matrix. In this comprehensive study that included XRD, chemical analyses, FTIR, and NMR spectroscopy, differences were found between young (1-3 months) and old (4-5 years) bovine mineral crystals and between cancellous and cortical bovine bone mineral of the same age.

From the XRD analysis we showed that bovine bone mineral crystal size increased with age and, on average, was larger or greater in cortical than cancellous bone. These results on bovine bone have comparable trends to that found in a rigorous, previous XRD study on 309 samples of cortical and trabecular human bone aged 0-90 years [31]. In that study human cancellous bone was found to be less crystalline than cortical bone aged 0-30 years due to greater bone remodeling activity in cancellous than cortical bone [31]. However, their XRD study mentions the presence of a significant amorphous phase that was not found in this study on bovine bone or our earlier study on very early bone cell culture deposited mineral [48]. This confirms the importance of removing the organic phase (using low-temperature, nonaqueous methods) when conducting XRD analyses since the organic matrix presence can confound accurate mineral characterization. For bones aged 30-80 years, they found only 
small differences in crystallinity parameters between cortical and cancellous and it was concluded that human bones reach maturity by 30 years [31]. The age after which maturational changes cease to be significant is important knowledge and may be the reason other studies have not shown differences in bone mineral of different ages. In our study, the crystal size increase was extremely significant between 1-3 month cancellous and cortical bone compared to that for 4-5 year cancellous and cortical bone. The 13 month cortical values were similar (yet still statistically different) to the $4-5$ year cortical bone values, indicating that the bovine cortical bones are close to reaching maturity by 1-3 months. A different study, also utilizing XRD, separated the fractions of bone by extent of mineralization percentage (i.e., age/maturity) using density gradient centrifugation and found no differences between cancellous and cortical bone crystals [23] or young and old [32] when the same density fractions from each were compared. A maturation process as a function of mineral/matrix ratio, or density fraction, was seen by some investigators [23, 49] but not others [32]. The lack of difference between young and old human bones in the latter study [32] may be due to comparing samples that were considered nearly mature by the standards of another study [31]. However, from these previous density fractionation studies we must conclude that, since our samples reflect pools of all density fractions within a given bone type, the major differences detected by XRD between the cancellous and cortical mineral crystals reflect the larger proportion of newly formed and less crystalline apatite found in cancellous bone compared to cortical bone of the same age.

The chemical analyses completed in our study on bovine mineral showed a statistically significant increase of $\mathrm{Ca} / \mathrm{P}$ ratios with age, with values that parallel those previously published for aging rat cortical bones (1.51 evolving to 1.69) [16]. We also found a statistically significant $(P=0.004)$ increase of $\mathrm{Ca} / \mathrm{P}$ ratio for cancellous vs. cortical bones, although age had less of an effect $(P=0.02)$, which is another indication that bovine cortical bones are nearing maturity by 1-3 months. The actual carbonate content varies from one animal species to another and with age within a given species [16]; however, the same trends are observed in our study as in Legros et al. [16] with regard to an increase of carbonate with age, which replaces the $\mathrm{HPO}_{4}$ ions as evidenced by the constant $\mathrm{C} / \mathrm{P}$ ratios. This effect was not significant in our study $(P=0.06)$ between cancellous and cortical bone of either age though.

From our analysis of the FTIR $v_{4}$ phosphate band ratios, not previously described for isolated cortical and cancellous samples, we found the labile $\mathrm{HPO}_{4}$ species were significantly reduced in the bovine cortical bone relative to the cancellous bone for the 1-3 month group. Statistical analysis indicated a significant interaction between age and bone type, meaning that age did not have the same effect at all values of bone type. Indeed, at 4-5 years the labile phosphate values were similar for both cancellous and cortical. The labile phosphate values were lower in bovine bone of both ages than previously published values for chicken bone $[17,25,26]$. The labile $\mathrm{PO}_{4}$ values did not show consistent trends. The FTIR carbonate analyses, in particular RF, indicate an increased crystallinity in older samples relative to young.

Our spectral analyses on isolated mineral are similar to those FTIR microspectroscopic studies on bone of various types $[20,36]$. The effect of a mixed population of young and old 
mineral crystals on accurate characterization of the mineral phase has been elucidated in previous FTIR and Raman microspectroscopic and microspectroscopic imaging studies [15, 19, 30, 36-40]. By separating the analysis of the bone into recently remodeled /deposited cancellous areas vs. recently remodeled /deposited cortical areas, a study concluded that the youngest/least crystalline cancellous mineral was similar to the youngest/least crystalline cortical mineral when using the 1,020/1,030 band ratio [30]. An analysis of the carbonate bands and the $v_{1}, v_{2}$ phosphate bands [15] revealed differences between young (4 weeks) and old ( 9 months) mouse mineral, which we have seen here in our chemical analyses and FTIR analyses of young (1-3 months) and old (4-5 years) bovine mineral. Namely, carbonate content was different between young cancellous and cortical bone, with less in younger bone, but in the older samples the carbonate contents had increased to the same levels in cortical and cancellous. While FTIR cannot provide quantitative chemical analysis, the agreement of our chemical analysis with the trends previously published from FTIR microspectroscopic analysis $[15,30]$ further validates FTIR imaging/microspectroscopic analysis of intact bone mineral (not isolated) as a means of making sensitive comparative measurements of the chemicophysical aspects of the mineral phase of bone.

The solid-state NMR data obtained in the present study along with the XRD and chemical data further confirmed the single-phase nature of the bone mineral at both ages and in both anatomic sites; however, it was not sensitive to aging or maturation phenomena. Additional insights may be gained with new solid-state NMR techniques [8] that permit the study of the mineral without the necessity of removing the matrix, thereby lessening the possibility that results could be affected by the plasma ashing or chemical matrix removal techniques.

\section{Conclusions}

To conclude, statistically significant differences were found, on average, between cancellous and cortical bovine bone mineral that varied with age. This study further validates that bone mineral undergoes a maturation process: the $\mathrm{Ca} / \mathrm{P}$ ratio of the carbonated apatite increases, the mineral becomes more crystalline, and crystal size increases. There are fewer labile phosphate groups and more incorporated carbonate ions in older bone mineral crystals. No other mineral phases were found. Bovine bone mineral reaches maturity at 1-3 months. The interpretation of the results for cancellous and cortical bone is not straightforward due to the inhomogeneity of bone with regard to the mixed presence of recently deposited mineral and mature mineral and the presence of more recently deposited bone in cancellous than in cortical bone, particularly at earlier ages. We therefore conclude that the differences between cortical and cancellous bone mineral should be ascribed to the different average age of the mineral crystals contained within the samples. There are no differences in the mineral component per se between cortical and cancellous bone when grouped by age/maturity.

\section{Supplementary Material}

Refer to Web version on PubMed Central for supplementary material. 


\section{Acknowledgements}

We thank Dr. Adele Boskey for her review of this manuscript and Dr. Jon Goldberg for his help with the statistical analysis. Supported in part by National Institutes of Health grants R01-AR34081, R01-AG14701, R01-AR42258, and T32-AR07112; a grant from the Peabody Foundation; the American Foundation for Aging Research; and the Orthopaedic Research and Education Foundation.

\section{References}

1. Glimcher MJ (1998) The nature of the mineral phase in bone: biological and clinical applications In: Alvioli L, Krane S (eds) Metabolic bone disease. Academic Press, New York, pp 23-50

2. LeGeros RZ (1991) Calcium phosphates in oral biology and medicine. Karger, Basel, p 110

3. Roufosse AH, Landis WJ, Sabine WK, Glimcher MJ (1979) Identification of brushite in newly deposited bone mineral from embryonic chicks. J Ultrastruct Res 68:235-255 [PubMed: 490754]

4. Bonar LC, Grynpas MD, Glimcher MJ (1984) Failure to detect crystalline brushite in embryonic chick and bovine bone by X-ray diffraction. J Ultrastruct Res 86:93-99 [PubMed: 6737562]

5. Biltz RM, Pellegrino ED (1971) The hydroxyl content of calcified tissue mineral. Calcif Tissue Res 36:259-263

6. Rey C, Miquel JL, Facchini L, Legrand AP, Glimcher MJ (1995) Hydroxyl groups in bone mineral. Bone 16:583-586 [PubMed: 7654473]

7. Loong C-K, Rey C, Kuhn LT, Combes C, Wu Y, Chen S-H, Glimcher MJ (2000) Evidence of hydroxyl-ion deficiency in bone apatites: an inelastic neutron scattering study. Bone 26:599-602 [PubMed: 10831931]

8. Cho G, Wu Y, Ackerman JL (2003) Detection of hydroxyl ions in bone mineral by solid-state NMR spectroscopy. Science 300:1123-1127 [PubMed: 12750514]

9. Wilson EE, Awonusi A, Morris MD, Kohn DH, Tecklenburg MM, Beck LW (2005) Highly ordered interstitial water observed in bone by nuclear magnetic resonance. J Bone Miner Res 20:625-634 [PubMed: 15765182]

10. Wu Y, Glimcher MJ, Rey C, Ackerman JL (1994) A unique protonated phosphate group in bone mineral not present in synthetic calcium phosphates. J Mol Biol 244:423-435 [PubMed: 7990131]

11. Roufosse AH, Aue WP, Roberts JE, Glimcher MJ, Griffin RG (1984) Investigation of the mineral phases of bone by solid-state phosphorus-31 magic angle sample spinning nuclear magnetic resonance. Biochemistry 23:6115-6120 [PubMed: 6525350]

12. Legros R, Bonel G, Montel G, Balmain-OLigo N, Juster M (1977) Systematic study of the variations in mineral composition of different bones from various animals according to their localization [in French]. C R Acad Sci Hebd Seances Acad Sci D 285:1519-1522 [PubMed: 417827]

13. Bigi A, Cojazzi G, Panzavolta S, Ripamonti A, Roveri N, Romanello M, Noris Suarez K, Moro L (1997) Chemical and structural characterization of the mineral phase from cortical and trabecular bone. J Inorg Chem 68:45-51

14. Mokrzynski S (1994) Analysis of mineral composition of femoral bones in the human fetus [in Polish]. An Acad Med Stetin 40:23-35

15. Boskey AL, Gadaleta S, Gundberg C, Doty SB, Ducy P, Karsenty G (1998) Fourier transform infrared microspectroscopy analysis of bones of osteocalcin-deficient mice provides insight into the function of osteocalcin. Bone 23:187-196 [PubMed: 9737340]

16. Legros R, Balmain N, Bonel G (1987) Age-related changes in mineral of rat and bovine cortical bone. Calcif Tissue Int 41:137-144 [PubMed: 3117340]

17. Rey C, Renugopalakrishnan V, Collins B, Glimcher MJ (1991) Fourier transform infrared spectroscopic study of the carbonate ions in bone mineral during aging. Calcif Tissue Int 49:251258 [PubMed: 1760769]

18. Boskey AL, DiCarlo E, Paschalis E, West P, Mendelsohn R (2005) Comparison of mineral quality and quantity in iliac crest biopsies from high- and low-turnover osteoporosis: an FT-IR microspectroscopic investigation. Osteoporos Int 16:2031-2038 [PubMed: 16088360] 
19. Tarnowski CP, Ignelzi MA, Jr, Morris MD (2002) Mineralization of developing mouse calvaria as revealed by Raman microspectroscopy. J Bone Miner Res 17:1118-1126 [PubMed: 12054168]

20. Miller LM, Vairavamurthy V, Chance MR, Mendelsohn R, Paschalis EP, Betts F, Boskey AL (2001) In situ analysis of mineral content and crystallinity in bone using infrared microspectroscopy of the $\mathrm{nu}_{4} \mathrm{PO}_{4}{ }^{3-}$ vibration. Biochim Biophys Acta 1527:11-19 [PubMed: 11420138]

21. Bonar LC, Roufosse AH, Sabine K, Grynpas MD, Glimcher MJ (1983) X-ray diffraction studies of the crystallinity of bone mineral in newly synthesized and density fractionated bone. Calcif Tiss Res 35:202-209

22. Grynpas MD (1976) The crystallinity of bone mineral. J Mater Sci 11:1691-1696

23. Bonar LC, Roufosse AN, Sabine WK, Grynpas MD, Glimcher MJ (1983) X-ray diffraction studies of the crystallinity of bone mineral in newly synthesized and density fractionated bone. Calcif Tissue Int 35:202-209 [PubMed: 6850400]

24. Matsushima N, Hikichi K (1989) Age changes in the crystallinity of bone mineral and in the disorder of its crystal. Biochim Biophys Acta 992:155-159 [PubMed: 2758062]

25. Rey C, Shimizu M, Collins B, Glimcher MJ (1990) Resolution enhanced Fourier transform infrared spectroscopy study of the environment of phosphate ions in the early deposits of a solid phase of calcium phosphate in bone and enamel and their evolution with age. 1: Investigations in the $v_{4} \mathrm{PO}_{4}$ domain. Calcif Tissue Int 46:384-394 [PubMed: 2364326]

26. Rey C, Shimizu M, Collins B, Glimcher MJ (1991) Resolution enhanced Fourier transform infrared spectroscopy study of the environment of phosphate ions in the early deposits of a solid phase of calcium phosphate in bone and enamel and their evolution with age. 2: Investigations in the $v_{3} \mathrm{PO}_{4}$ domain. Calcif Tissue Int 49:383-388 [PubMed: 1818762]

27. Rey C, Hina A, Tofighi A, Glimcher MJ (1995) Maturation of poorly crystalline apatites: chemical and structural aspects in vivo and in vitro. Cells Mater 5:345-356

28. Rey C, Glimcher MJ (1992) Short range organization of the Ca-P mineral phase in bone and enamel: changes with age and maturation In: Slavkin H, Price P (eds) Chemistry and biology of mineralized tissues. Elsevier, San Diego, pp 5-18

29. Cazalbou S, Combes C, Eichert D, Rey C, Glimcher MJ (2004) Poorly crystalline apatites: evolution and maturation in vitro and in vivo. J Bone Miner Metab 22:310-317 [PubMed: 15221488]

30. Paschalis EP, Betts F, DiCarlo E, Mendelsohn R, Boskey AL (1997) FTIR microspectroscopic analysis of normal human cortical and trabecular bone. Calcif Tissue Int 61:480-486 [PubMed: 9383275]

31. Handschin RG, Stern WB (1992) Crystallographic lattice refinement of human bone. Calcif Tissue Int 51:111-120 [PubMed: 1422949]

32. Simmons ED, Jr, Pritzker KPH, Grynpas MD (1991) Age-related changes in the human femoral cortex. J Orthop Res 9:155-167 [PubMed: 1992064]

33. Lundon K, Dumitriu M, Grynpas MD (1997) Supraphysiologic levels of testosterone affect cancellous and cortical bone in the young female cynomolgus monkey. Calcif Tissue Int 60:54-62 [PubMed: 9030481]

34. Kim H-M, Rey C, Glimcher MJ (1995) Isolation of calcium-phosphate crystals of bone by nonaqueous methods at low temperature. J Bone Miner Res 10:1589-1601 [PubMed: 8686516]

35. Boskey AL, Mendelsohn R (2005) Infrared spectroscopic characterization of mineralized tissues. Vib Spectrosc 38:107-114 [PubMed: 16691288]

36. Ou-Yang H, Paschalis EP, Mayo WE, Boskey AL, Mendelsohn R (2001) Infrared microscopic imaging of bone: spatial distribution of $\mathrm{CO}_{3}^{2-}$. J Bone Miner Res 16:893-900 [PubMed: 11341334]

37. Ouyang H, Sherman PJ, Paschalis EP, Boskey AL, Mendelsohn R (2004) Fourier transform infrared microscopic imaging: effects of estrogen and estrogen deficiency on fracture healing in rat femurs. Appl Spectrosc 58:1-9 [PubMed: 14727714]

38. Awonusi A, Morris MD, Tecklenburg MM (2007) Carbonate assignment and calibration in the Raman spectrum of apatite. Calcif Tissue Int 81:46-52 [PubMed: 17551767] 
39. Paschalis EP, DiCarlo E, Betts F, Sherman P, Mendelsohn R, Boskey AL (1996) FTIR microspectroscopic analysis of human osteonal bone. Calcif Tissue Int 59:480-487 [PubMed: 8939775]

40. Camacho NP, Rinnerthaler S, Paschalis EP, Mendelsohn R, Boskey AL, Fratzl P (1999) Complementary information on bone ultrastructure from scanning small angle X-ray scattering and Fourier-transform infrared microspectroscopy. Bone 25:287-293 [PubMed: 10495132]

41. Boskey AL, Moore DJ, Amling M, Canalis E, Delany AM (2003) Infrared analysis of the mineral and matrix in bones of osteonectin-null mice and their wildtype controls. J Bone Miner Res 18:1005-1011 [PubMed: 12817752]

42. Wu Y, Ackerman JL, Strawich ES, Rey C, Kim HM, Glimcher MJ (2003) Phosphate ions in bone: identification of a calcium-organic phosphate complex by ${ }^{31} \mathrm{P}$ solid-state NMR spectroscopy at early stages of mineralization. Calcif Tissue Int 72:610-626 [PubMed: 12724829]

43. Kaflak A, Chmielewski D, Górecki A, Kolodziejski W (1998) Kinetics of ${ }^{1} \mathrm{H}-{ }^{31} \mathrm{P}$ cross polarization in human trabecular bone. Solid State Nucl Magn Reson 10:191-195 [PubMed: 9603619]

44. Wu Y, Ackerman JL, Kim H-M, Rey C, Barroug A, Glimcher MJ (2002) Nuclear magnetic resonance spin-spin relaxation of the crystals of bone, dental enamel and synthetic hydroxyapatites. J Bone Miner Res 17:472-480 [PubMed: 11874238]

45. Engleman EE, Jackson LL, Norton DR (1985) Determination of carbonate carbon in geological materials by coulometric titration. Chem Geol 53:125-128

46. Klug HP, Alexander LE (1974) X-ray diffraction procedures for polycrystallite and amorphous materials, 2nd edn. Wiley, New York

47. Rey C, Collins B, Goehl T, Dickson IR, Glimcher MJ (1989) The carbonate environment in bone mineral: a resolution enhanced Fourier transform infrared spectroscopy study. Calcif Tissue Int 45:157-164 [PubMed: 2505907]

48. Kuhn LT, Wu Y, Rey C, Gerstenfeld LC, Grynpas MD, Ackerman JL, Kim HM, Glimcher MJ (2000) Structure, composition and maturation of newly deposited calcium-phosphate crystals in chicken osteoblast cell cultures. J Bone Miner Res 15:1301-1309 [PubMed: 10893678]

49. Repo MA, Bockman RS, Betts F, Boskey AL, Alcock NW, Warrel RP, Jr (1988) Effect of gallium on bone mineral properties. Calcif Tissue Int 43:300-306 [PubMed: 3145797] 


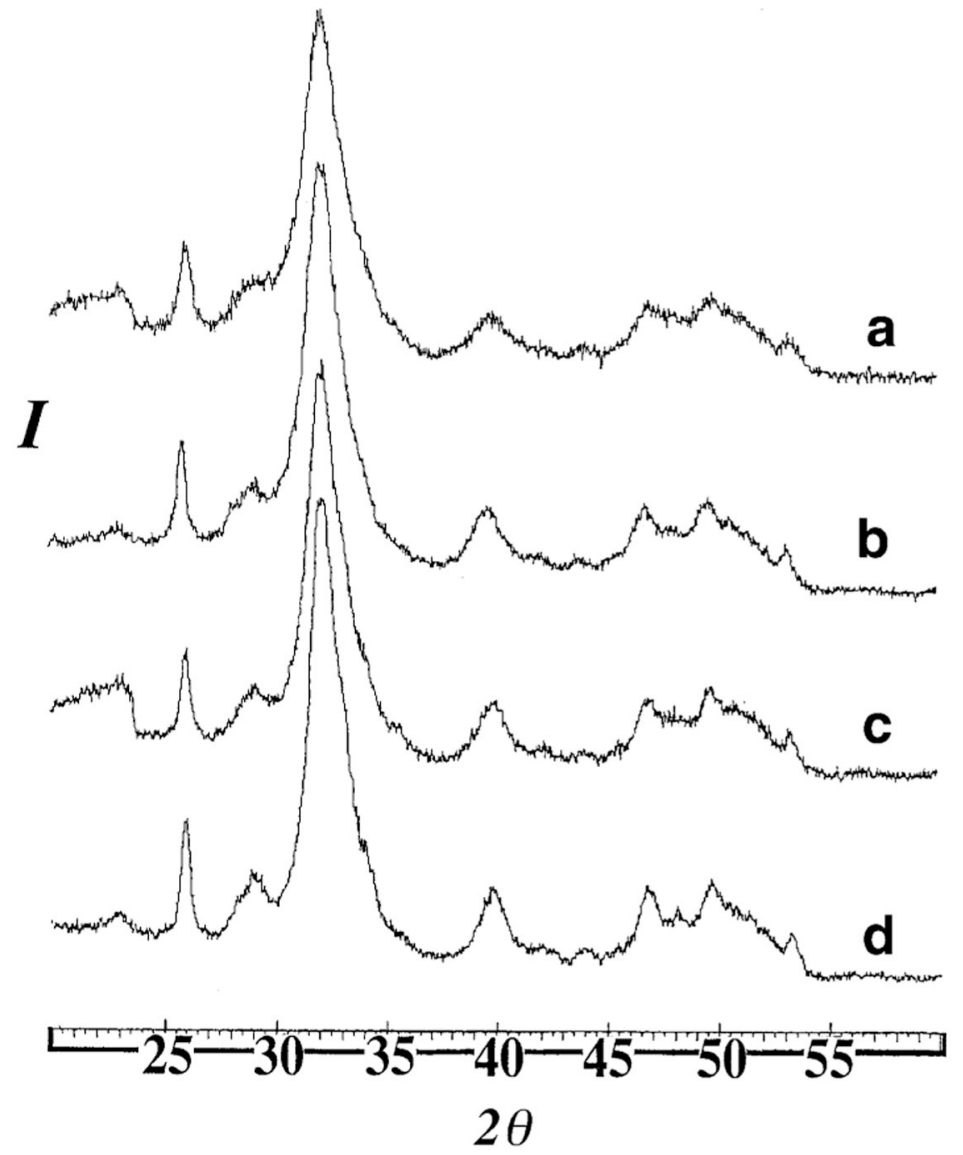

Fig. 1.

XRD spectra of isolated bone mineral from (a) 1-3 month cancellous bone, (b) 1-3 month cortical bone, (c) 4-5 year cancellous bone, and (d) 4-5 year cortical bone. The patterns are all apatitic, but a sharpening of the 002 peak $\left(\sim 26^{\circ} 2 \theta\right)$ is evident of increased crystallinity of the older and cortical bone samples 


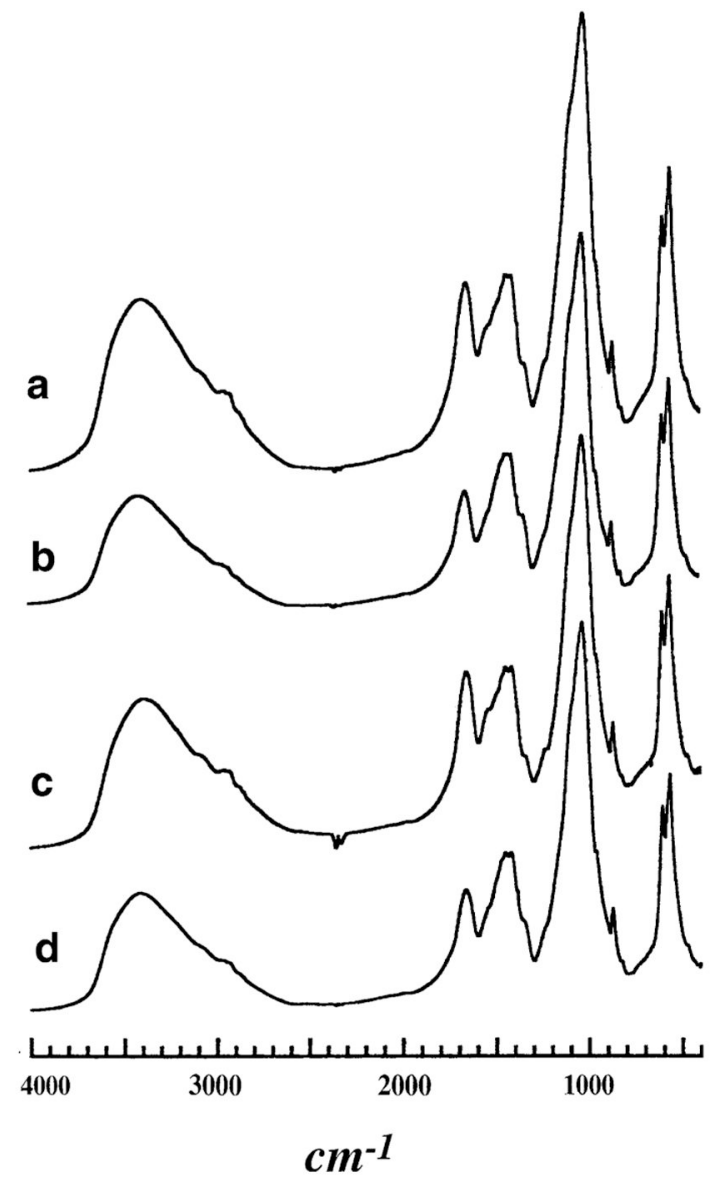

Fig. 2.

FTIR spectra of isolated bone mineral from (a) 1-3 month cancellous bone, (b) 1-3 month cortical bone, (c) 4-5 year cancellous bone, and (d) 4-5 year cortical bone. The patterns are all apatitic. Deconvolution and decomposition of the $v_{2}$ carbonate and $v_{4}$ phosphate domains is required to detect differences between the samples, shown in Table 2 

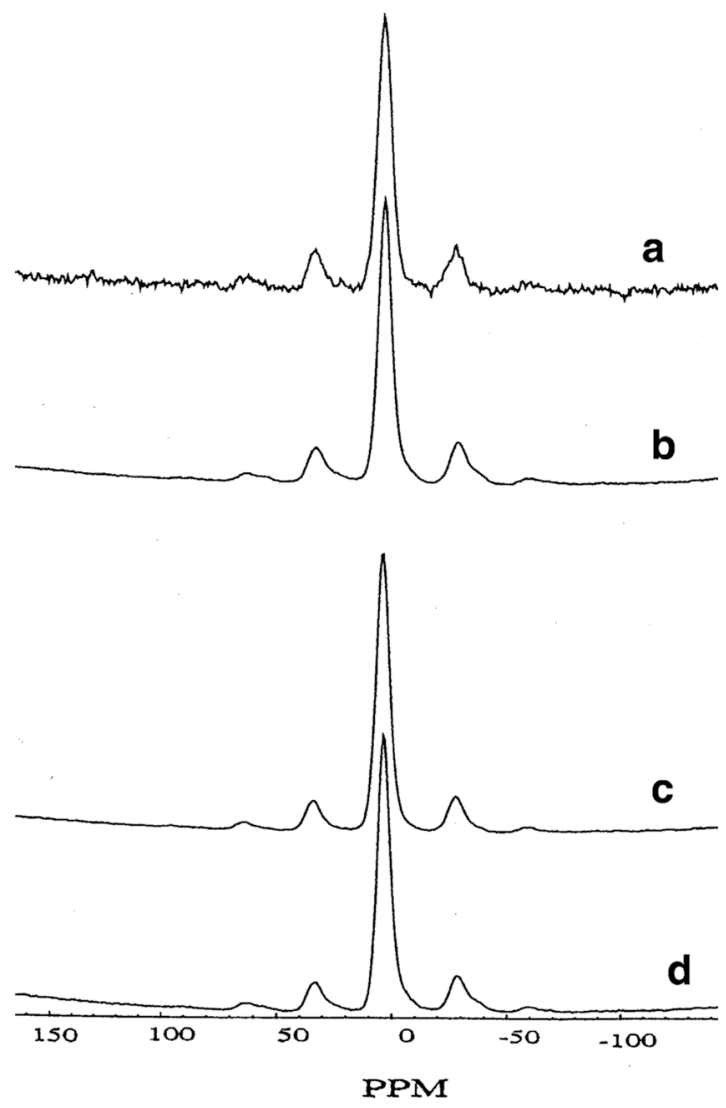

Fig. 3.

${ }^{31} \mathrm{P}$ NMR normal CP spectra from (a) 1-3 month cancellous bone, (b) 1-3 month cortical bone, (c) 4-5 year cancellous bone, and (d) 4-5 year cortical bone. The patterns are all apatitic with an isotropic chemical shift of $3.1 \mathrm{ppm}$, identical to the chemical shift of hydroxyapatite 

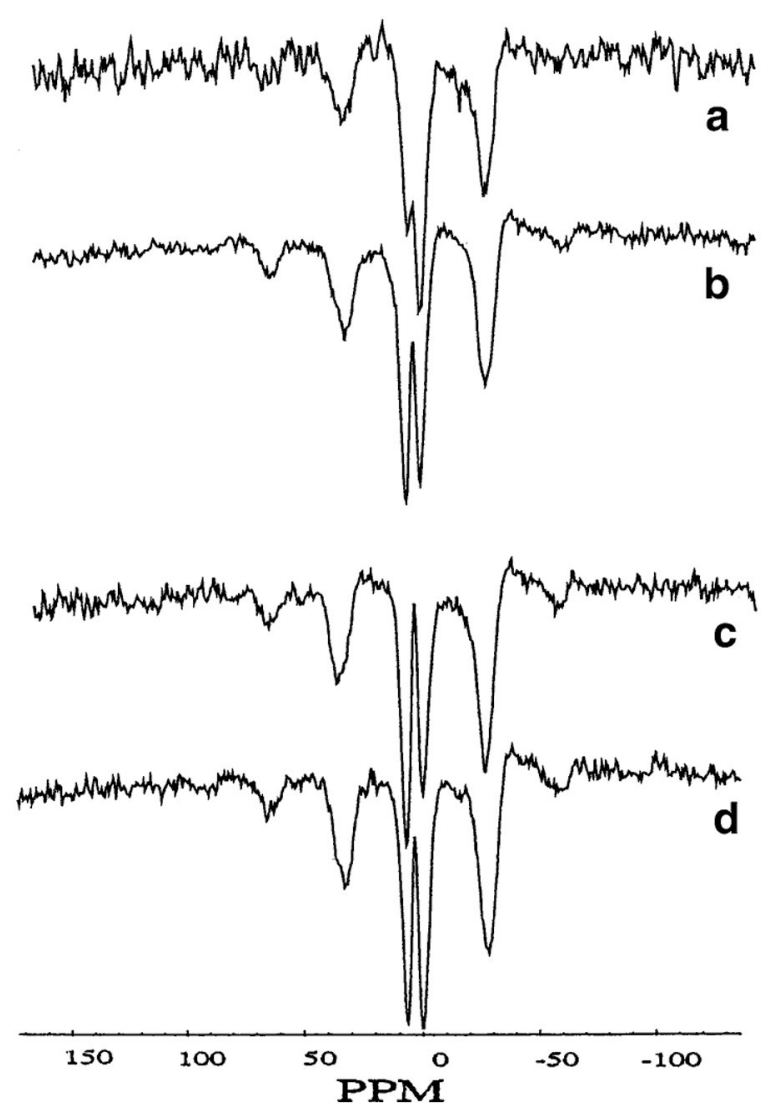

Fig. 4.

${ }^{31} \mathrm{P}$ NMR differential CP spectra from (a) 1-3 month cancellous bone, (b) 1-3 month cortical bone, (c) 4-5 year cancellous bone, and (d) 4-5 year cortical bone. The prominent inverted spinning sideband pattern is characteristic of apatitic $\mathrm{HPO}_{4}$. The narrow positivegoing spectral feature overlapping the $\mathrm{HPO}_{4}$ center-band is the centerband of $\mathrm{PO}_{4}$, which is not inverted at this reverse $\mathrm{CP}$ time. The upfield first-order sidebands are more intense than the downfield first-order sidebands, characteristic of calcium ion in close association with the phosphorus atoms 


\section{Table 1}

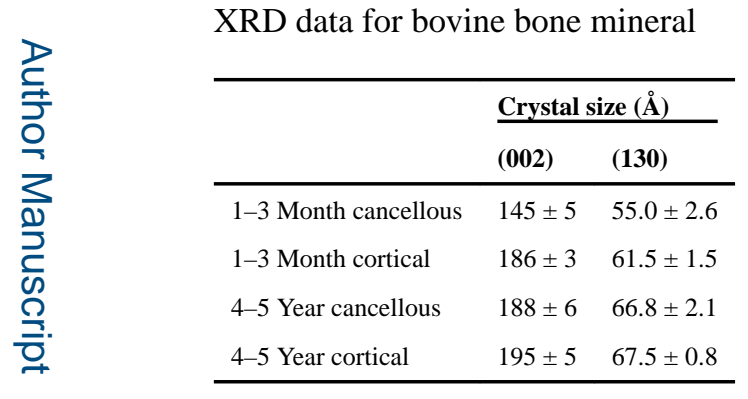


Table 2

Chemical composition data for bovine bone mineral

\begin{tabular}{llllll}
\hline & $\mathbf{C a} / \mathbf{P}$ & $\mathbf{C a} /(\mathbf{P}+\mathbf{C})$ & $\mathbf{\%} \mathbf{C O}_{\mathbf{3}}$ & $\mathbf{C} / \mathbf{P}( \pm \mathbf{0 . 0 0})$ & Residual protein $(\boldsymbol{\%})$ \\
\hline 1-3 Month cancellous & $1.51 \pm 0.04$ & $1.31 \pm 0.04$ & $4.75 \pm 0.06$ & 0.15 & 10.5 \\
1-3 Month cortical & $1.61 \pm 0.03$ & $1.39 \pm 0.02$ & $5.03 \pm 0.07$ & 0.16 & 2.3 \\
4-5 Year cancellous & $1.58 \pm 0.06$ & $1.33 \pm 0.08$ & $5.33 \pm 0.18$ & 0.17 & 14.6 \\
4-5 Year cortical & $1.64 \pm 0.02$ & $1.41 \pm 0.01$ & $5.33 \pm 0.10$ & 0.17 & 3.8 \\
\hline
\end{tabular}


Table 3

FTIR carbonate and phosphate band ratios

\begin{tabular}{llllll}
\hline & $\mathbf{A} / \mathbf{B ~ C O}_{\mathbf{3}}(\mathbf{\pm 1 \%})$ & $\mathbf{C} / \mathbf{B ~ C O}_{\mathbf{3}}(\mathbf{\pm 1 \%})$ & $\mathbf{R e s ~ F}$ & ${\boldsymbol{\% ~ L a b i l e ~} \mathbf{H P O}_{\mathbf{4}}}$ & \% Labile $\mathbf{P O}_{\mathbf{4}}$ \\
\hline 1-3 Month cancellous & $\mathrm{nm}$ & $\mathrm{nm}$ & $\mathrm{nm}$ & $23.6 \pm 0.2$ & $10.2 \pm 0.1$ \\
1-3 Month cortical & 0.80 & 0.78 & 0.46 & $21.1 \pm 0.2$ & $10.0 \pm 0.1$ \\
4-5 Year cancellous & $\mathrm{nm}$ & $\mathrm{nm}$ & $\mathrm{nm}$ & $20.7 \pm 0.2$ & $8.7 \pm 0.1$ \\
4-5 Year cortical & 0.83 & 0.76 & 0.50 & $20.3 \pm 0.2$ & $9.6 \pm 0.1$ \\
\hline
\end{tabular}

$\mathrm{nm}$, not measured due to spectral interference at this wavelength 